\title{
Basic Concepts and Interfacial Aspects of High-Efficiency III-V Multijunction Solar Cells
}

\author{
B. Erol Sağol, Ulf Seidel, Nadine Szabó, Klaus Schwarzburg, and Thomas Hannappel ${ }^{\star}$
}

\begin{abstract}
Among various types of solar cells, MOVPE-grown triple-junction III-V compound semiconductors are today's most efficient photovoltaic devices with conversion efficiencies exceeding $40 \%$. A next-generation multijunction cell with four or more junctions and optimized band gaps is expected to break the present record efficiency surpassing the $50 \%$ mark. High band gap material combinations that are lattice matched to GaAs are already well established, but the required low band gap combinations containing a band gap around $1 \mathrm{eV}$ are still to be improved. For this purpose, we have developed a low band gap tandem (two-junction) solar cell lattice matched to InP. For the top and bottom subcells InGaAsP $\left(E_{g}=1.03 \mathrm{eV}\right)$ and $\operatorname{InGaAs}\left(E_{g}=0.73 \mathrm{eV}\right)$ were utilized, respectively. A new interband tunnel junction was used to connect the subcells, including thin and highly doped layers of n-type InGaAs and p-type GaAsSb. The delicate MOVPE preparation of critical interfaces was monitored with in-situ reflectance anisotropy spectroscopy (RAS). After a contamination-free transfer, the RAS signals were then benchmarked in ultrahigh vacuum (UHV) with surface science techniques like low energy electron diffraction (LEED) and X-ray photoelectron spectroscopy (XPS). XPS measurements revealed that the sharpest InGaAs/ $\mathrm{GaAsSb}$ interface was achieved when the GaAsSb layer in the tunnel junction of the solar cell was grown on III-rich $(2 \times 4)$ - or (4×2)-reconstructed InGaAs(100) surfaces. The improved interface preparation had a positive impact on the overall performance of the tandem cell, where slightly higher efficiencies were observed for the cells with the III-rich-prepared tunnel junction interfaces.
\end{abstract}

Keywords: InP-based materials · Low energy electron diffraction · Metal organic vapor phase epitaxy · Reflectance anisotropy spectroscopy · III-V Solar cells · Surface reconstruction

\section{Introduction}

Among various types of solar cells, multijunction solar cells fabricated from IIIV compound semiconductors are today's most efficient photovoltaic devices. ${ }^{[1]}$ They are already well established and widely used as space solar cells, ${ }^{[2]}$ and have a significant market potential for terrestrial

${ }^{\star}$ Correspondence: Dr. T. Hannappe

Hahn-Meitner-Institute

Glienicker Str. 100

D-14109 Berlin, Germany

Tel.: +49308062 2674

Fax: +49 3080622434

E-Mail: hannappel@hmi.de applications. ${ }^{[3]}$ III-V compounds offer superior properties in terms of material quality, stability, radiation hardness, miscibility, and tunability of band gaps $v s$. lattice constants (band gap engineering). It is possible to realize a broad range of materials with different band gap energies $\left(\mathrm{E}_{\mathrm{g}}\right)$ that can be grown monolithically either lattice matched or lattice mismatched (metamorphic) on $\mathrm{Si}$, $\mathrm{Ge}, \mathrm{GaAs}$, and InP substrates. One of the ways to boost the conversion efficiency beyond the Shockley-Queisser limit ${ }^{[4]}$ is to connect multiple solar cells with band gaps optimized for different spectral regions of the solar spectrum. This in turn reduces the inherent transmission and thermal losses of conventional single-junction solar cells and therefore increases the conversion efficiency. Besides, high minority carrier lifetimes, i.e. minimum defect density of the bulk material, and sharp and well defined interfaces, e.g. minimized interdiffusion through buried interfaces, are major key points for a state-of-the-art III-V solar cell.

Recently, two types of III-V multijunction solar cells in the form of an InGaP/In$\mathrm{GaAs} / \mathrm{Ge}$ triple-junction configuration have surpassed the $40 \%$ conversion efficiency barrier. ${ }^{[5]}$ One of them was grown lattice matched to Ge having an efficiency of $40.1 \%$, and the other one was grown metamorphically on Ge having an even better efficiency with $40.7 \%$. ${ }^{[5]}$ Still higher efficiencies may be reached if more than three appropriate subcells with optimized band gaps are used. ${ }^{6]}$ For a four-junction configuration a suitable material with a band gap of around $1 \mathrm{eV}$ is required. InGaAsN, a dilute nitride compound, is a possible candidate that can be grown lattice matched to Ge. However, the transport properties, i.e. charge carrier lifetimes and diffusion lengths, of this material have not yet been sufficient for solar cell applications. ${ }^{[7,8]} \mathrm{Al}$ ternatively, compounds that are grown lattice matched to InP can easily provide the required low band gap materials $(0.7 \mathrm{eV}<$ $\mathrm{E}_{\mathrm{g}}<1.4 \mathrm{eV}$ ). For a four-junction (or more) configuration, the high band gap tandem cell can be grown on GaAs and the low band gap tandem cell on InP. These two subcells with different lattice constants could then be combined in a four-junction configuration by means of grading, ${ }^{[9]}$ spectral beam 
splitting, ${ }^{[10]}$ mechanical stacking, ${ }^{[11]}$ or wafer bonding. ${ }^{[12]}$

\section{Cell Concept}

Based on the thermodynamical detailed balance theory, ${ }^{[4]}$ a routine for calculating the limiting efficiencies and optimum band gap energies of multijunction solar cells has been developed (EtaOpt). ${ }^{[13,14]}$ Using this routine the limiting efficiencies and optimum band gap energies of monolithic triple-junction cells and mechanically stacked four-junction cells (as shown in the insets of Fig. 1) were calculated for a AM1.5d solar spectrum, at a concentration of 500 suns and a cell temperature of $50{ }^{\circ} \mathrm{C}$. Fig. 1a displays the contour lines of the limiting efficiencies for the triplejunction solar cells as a function of the band gaps of the middle and top subcells. The band gap of the bottom cell is fixed to $0.65 \mathrm{eV}(\mathrm{Ge})$. As seen from the contour plot, the lattice-matched (LM) configuration $\mathrm{In}_{0.50} \mathrm{Ga}_{0.50} \mathrm{P} / \mathrm{In}_{0.01} \mathrm{Ga}_{0.99} \mathrm{As} / \mathrm{Ge}$ having a theoretical limiting efficiency of $46 \%$ is far from the maximum value. So far, the best experimental conversion efficiency obtained for these cells was $40.1 \% .^{\text {[5] One }}$ of the methods to improve the efficiency is to increase the In content of the middle and top subcells. This decreases the band gaps of the subcells following the indicated black line, and therefore increases the efficiency because the band gaps approach the optimum point. However, this also increases the lattice constant of the grown materials causing them to become lattice-mismatched/metamorphic (MM), and thereby introduces extra defects. Currently, the best triple-junction $\mathrm{MM}$ cell is an $\mathrm{In}_{0.56} \mathrm{Ga}_{0.44} \mathrm{P} /$ $\mathrm{In}_{0.08} \mathrm{Ga}_{0.92} \mathrm{As} / \mathrm{Ge}$ solar cell, which also holds the current world record conversion efficiency with $40.7 \%$. [5] It has a theoretical limiting efficiency of $46 \%$, which is still far from the maximum value.

As shown in Fig. 1a, the maximum theoretical limiting efficiency is given for the band gap combination of $1.15 \mathrm{eV}$ and $1.65 \mathrm{eV}$ for the middle and top subcells, respectively. This corresponds to the material combination $\mathrm{In}_{0.67} \mathrm{Ga}_{0.33} \mathrm{P} / \mathrm{In}_{0.20} \mathrm{Ga}_{0.80} \mathrm{As} /$ $\mathrm{Ge}$ and has a high lattice-mismatch of $\Delta \mathrm{a} / \mathrm{a}$ $\cong 1.5 \%$. There have been successful efforts to grow very similar $\mathrm{MM} \mathrm{In}_{0.65} \mathrm{Ga}_{0.35} \mathrm{P} /$ $\mathrm{In}_{0.17} \mathrm{Ga}_{0.83} \mathrm{As}$ tandem solar cells on $\mathrm{GaAs}^{[15]}$ and $\mathrm{In}_{0.71} \mathrm{Ga}_{0.29} \mathrm{P} / \mathrm{In}_{0.23} \mathrm{Ga}_{0.77} \mathrm{As} /$ Ge triple-junction solar cells on $\mathrm{Ge},{ }^{[i 6]}$ but their efficiencies did not exceed the efficiencies of their LM counterparts due to the high lattice-mismatch that introduces additional growth defects. However, by improving the material quality, metamorphically grown III-V multijunction solar cells are expected to continue breaking new efficiency records.
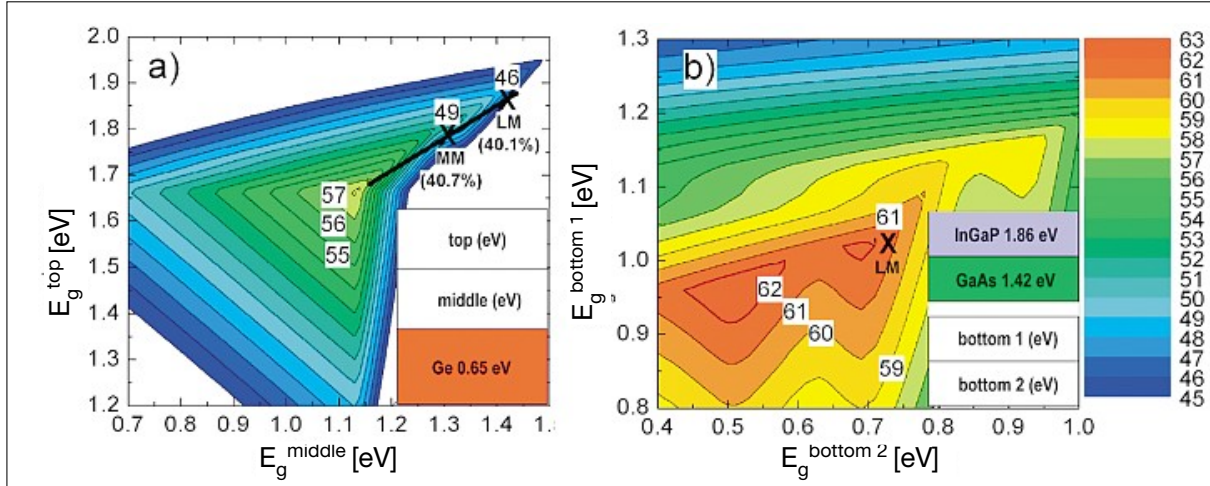

Fig. 1. a) Contour lines of calculated limiting conversion efficiencies of ideal monolithic triplejunction solar cells under $500 \times \mathrm{AM} 1.5 \mathrm{~d}$ at $50{ }^{\circ} \mathrm{C}$. Values in parentheses are the best experimental efficiency values for lattice matched (LM) and metamorphic (MM) InGaP/InGaAs/Ge solar cells. ${ }^{[5]}$ b) Corresponding calculations for ideal mechanically stacked four-junction solar cells. The cross corresponds to the herein proposed LM InGaAsP/InGaAs bottom cell built under a LM InGaP/GaAs top cell.

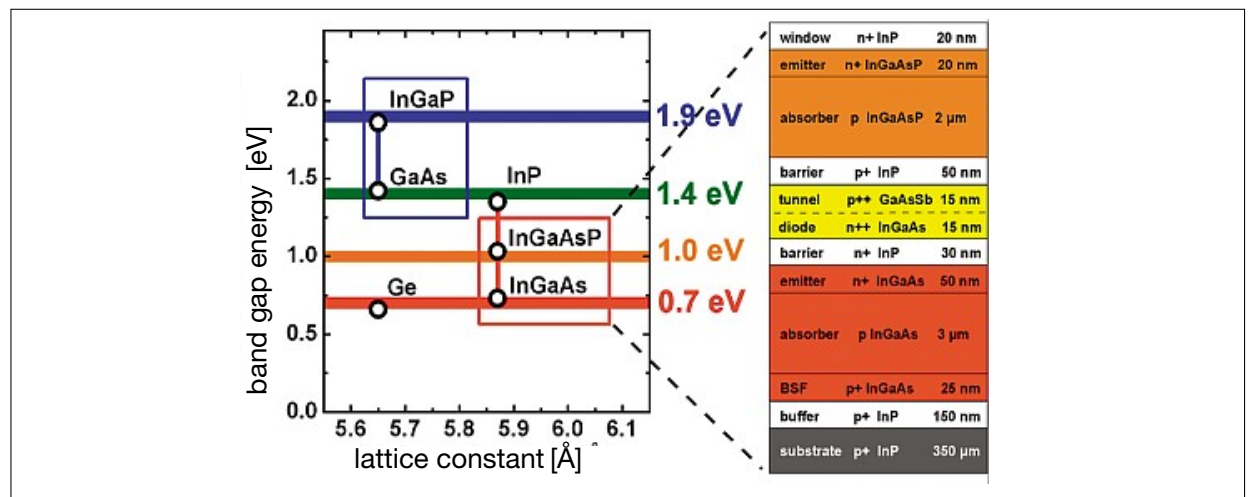

Fig. 2. Left: Optimum band gap energies for a four-junction solar cell configuration. The high band gap tandem can be grown lattice matched to GaAs and the low band gap tandem lattice matched to InP. Right: The device structure of the low band gap tandem cell.

On the other hand, even higher limiting conversion efficiencies are achievable for the four-junction cell configuration under the same operating conditions. In Fig. 1b the band gaps of the well-established lattice matched InGaP/GaAs tandem top cell are fixed $(1.86 \mathrm{eV}$ and $1.42 \mathrm{eV})$, and the band gaps of the bottom tandem cell are varied. As seen from the contour lines, the limiting efficiency of the here suggested material combination, which is latticematched to InP and marked with the cross $\left(\mathrm{E}_{\mathrm{g}}^{\text {bottom1 }}=1.03 \mathrm{eV}\right.$ and $\mathrm{E}_{\mathrm{g}}^{\text {bottom2 }}=0.73$ $\mathrm{eV}$, is around $61 \%$ and very close to the maximum value. Fig. 2 illustrates this optimal band gap combination for the double tandem (four-junction) cell. Our work is dedicated to the realization of the lower tandem (right hand side of Fig. 2).

The established way to combine the individual subcells of a monolithically grown multijunction cell is to connect them in series via an Esaki interband tunnel diode. ${ }^{[17]}$ The tunnel diode should feature both a low electrical resistivity and a high optical transmissivity, and should be able to carry current densities of several $10 \mathrm{~A} /$ $\mathrm{cm}^{2}$, to sustain concentration ratios up to 500-1000 suns. Fig. 3 shows the simulation of the band structure of the specific tunnel junction that connects the InGaAsP and InGaAs subcells in our tandem solar cell. Among other possible InP-based material combinations, the highly doped $\mathrm{n}^{++}$ InGaAs $(15 \mathrm{~nm})$ and $\mathrm{p}^{++}-\mathrm{GaAsSb}(15 \mathrm{~nm})$ heterostructure was chosen, because corresponding simulations forecast the shortest tunneling distance and thus the lowest electrical resistivity. ${ }^{[18]}$ However, the low band gap of this tunnel junction absorbs a small portion of light that is supposed to reach the bottom cell, but this loss reduces the limiting conversion efficiency in Fig $1 \mathrm{~b}$ by about only $0.3 \%$ absolute. The tunnel diode is embedded between two InP layers that act as reflecting barriers for the photogenerated minority carriers. For a good performance of the tunnel junction, the interface between the thin InGaAs and GaAsSb layers has to be as abrupt as possible. 


\section{Experimental Methods}

InGaAsP/InGaAs tandem solar cells were grown monolithically on p-doped InP (100) wafers by metal organic vapor phase epitaxy (MOVPE). A commercial AIX-200 MOVPE reactor was used for the growth of the structures with a hydrogen carrier gas pressure of 50 mbar and a total flow of 5.5 $\mathrm{sl} / \mathrm{min}$. The precursors were trimethylindium (TMIn), triethylgallium (TEGa), tertiarybutylphosphine (TBP), tertiarybutylarsine (TBAs) and triethylantimony (TESb). For the $\mathrm{p}$ - and n-doping diethylzinc (DEZn) and ditertiarybutylsilane (DTBSi) were utilized, respectively. However, for high pdoping levels of the GaAsSb layers, carbon tetrabromide $\left(\mathrm{CBr}_{4}\right)$ was employed. The growth process was monitored in situ via reflectance anisotropy spectroscopy (RAS) with a LayTec EpiRAS 200 spectrometer. The device structure is shown in Fig. 2.

For surface science analysis, the samples were transferred from the MOVPE reactor to ultra high vacuum (UHV) employing a patented transfer system. ${ }^{[19]}$ The MOVPE-grown surfaces were then characterized by low energy electron diffraction (LEED) to monitor the symmetry of the surface reconstructions and by X-ray photoelectron spectroscopy (XPS) to measure the chemical composition of the surface.

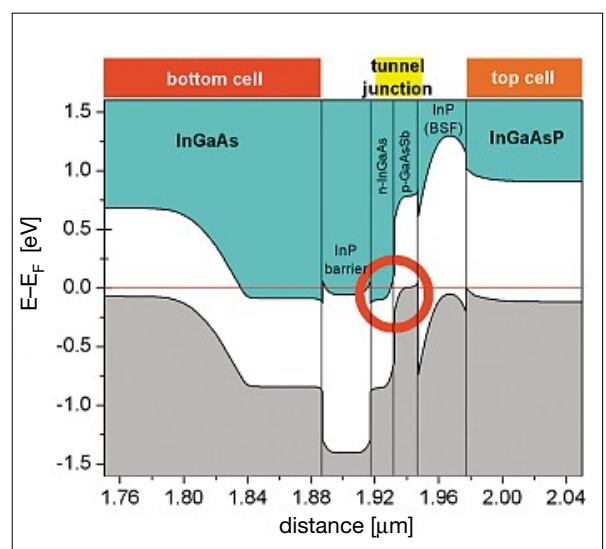

Fig. 3. Simulation of the band structure of the tunnel junction that connects the subcells of the InGaAsP/InGaAs tandem solar cell. The tunneling region is highlighted with the red circle.

The LEED patterns were recorded using a digital video camera with reverse view LEED optics, whereas the XP spectra of As 3d, Sb 4d, In 3d, and Ga 2p core levels were acquired with a hemispherical energy analyzer (Specs, Phoibos 100). An X-ray source emitting $\mathrm{Mg} \mathrm{K} \mathrm{K}_{\alpha}$ radiation (hv = $1253.6 \mathrm{eV}$ ) was employed for the excitation of the samples, and Voigt line shapes were fitted to the XP spectra of the core levels to calculate the XPS peak areas.

The experimental procedure to study the growth and interfaces of the tunnel junction is depicted in Fig. 4. In the first step, different InGaAs surfaces were prepared via MOVPE and analyzed in situ by employing RAS. After the transfer of the samples to UHV, the corresponding surface reconstructions were identified by LEED and the chemical composition by XPS. This kind of 'benchmarking' was necessary to interpret the RAS signals, which cannot be understood intuitively. In the next step, the growth of the GaAsSb layers on different InGaAs surface reconstructions was investigated by employing the same experimental strategy. Finally, the influence of different interface preparation routes both on the sharpness of the tunnel junction and on the solar cell performance was studied.

\section{Results and Discussion}

\subsection{MOVPE Prepared InGaAs Surfaces and GaAsSb Layers}

For the investigation of the InGaAs surface reconstructions, $300 \mathrm{~nm}$ thick InGaAs layers were grown lattice-matched on InP (100) substrates at $600{ }^{\circ} \mathrm{C}$ as shown in Fig. 4. Just after the growth, the samples were

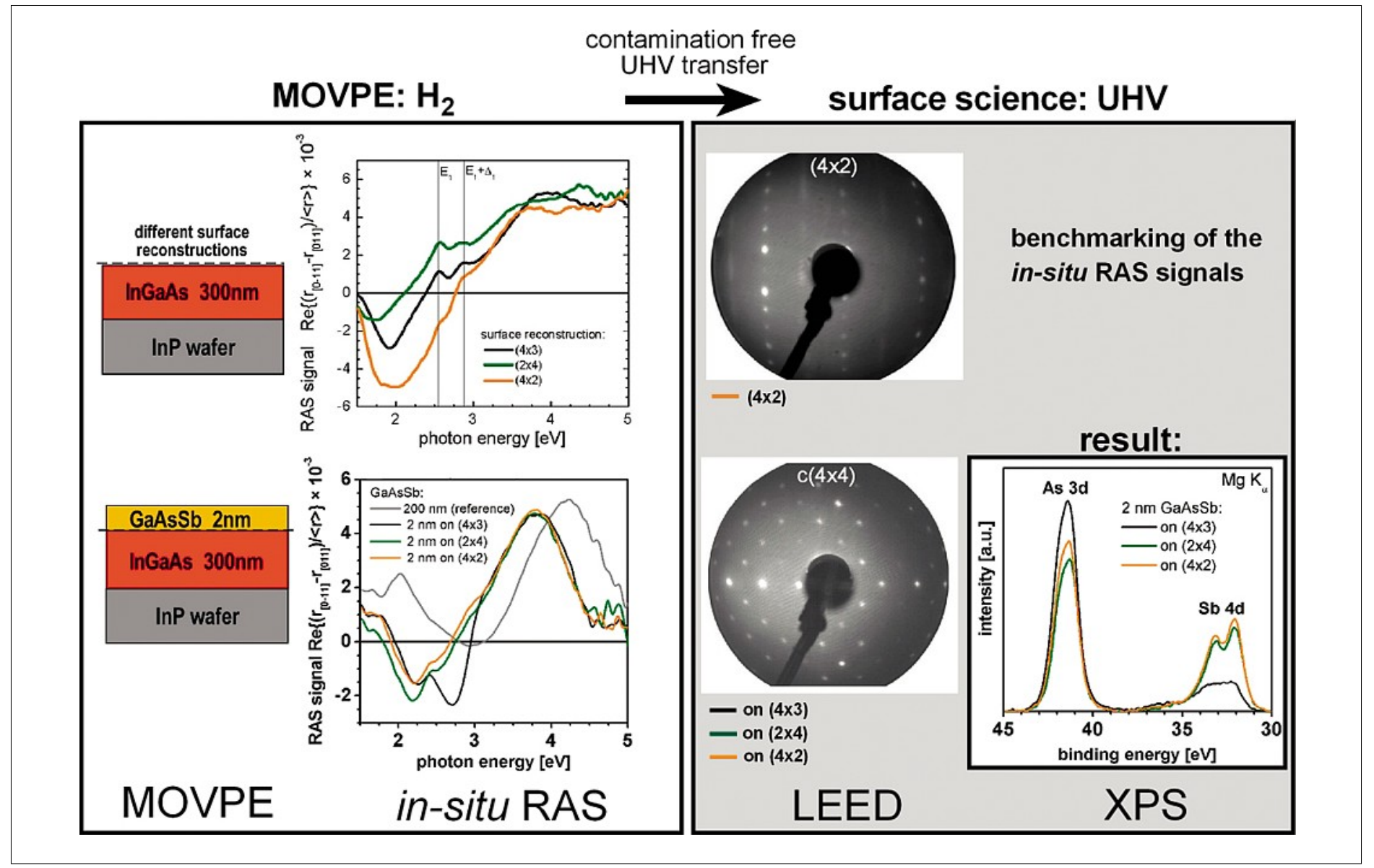

Fig. 4. Experimental procedure: The critical interface of the tunnel junction was investigated, first in the MOVPE reactor (left hand side) by employing in situ RAS, then in UHV (right hand side) by using LEED and XPS, after a contamination-free transfer. 
cooled down to $300{ }^{\circ} \mathrm{C}$ under TBAs stabilization. Then, the TBAs flow was switched off and the temperature was ramped from $300{ }^{\circ} \mathrm{C}$ to $700{ }^{\circ} \mathrm{C}$ with $1.5{ }^{\circ} \mathrm{C} / \mathrm{min}$ under pure hydrogen ambience while measuring continuously with in situ RAS. As seen in the top graph of Fig. 4, three distinct RA spectra were observed for three temperature regimes corresponding to three different surface reconstructions. To identify the different surface reconstructions, the surface of the samples was investigated with LEED. ${ }^{[20]}$ For this purpose, three different InGaAs surfaces were prepared as described above, but the ramp was interrupted at different critical temperatures. The samples were then immediately transferred contamination-free to UHV for LEED experiments. An As-rich (4×3)-reconstructed surface was observed for annealing temperatures below $390{ }^{\circ} \mathrm{C}$. Increasing the sample temperature beyond $390{ }^{\circ} \mathrm{C}$ led to a $(2 \times 4)$-reconstructed surface. Temperatures higher than $500{ }^{\circ} \mathrm{C}$ produced a well-ordered III-rich InGaAs surface with a $(4 \times 2) / \mathrm{c}(8 \times 2)$-reconstruction. The latter, which is shown in the top LEED picture of Fig. 4, will be denoted simply as the $(4 \times 2)$-reconstruction in the following. Possible atomic models corresponding to these surface reconstructions can be found in the literature ${ }^{[21-23]}$ and will be discussed elsewhere.

In the next step, the growth of the GaAsSb layers on the three different InGaAs surface reconstructions was studied. As shown on the bottom left side of Fig. 4 , very thin $(2 \mathrm{~nm}) \mathrm{GaAsSb}$ layers were grown lattice-matched on the three different InGaAs surfaces that were prepared as described above. The growth temperature for the GaAsSb layers was chosen to be $500{ }^{\circ} \mathrm{C}$, which was optimized in a previous study. ${ }^{[24]}$ The RA spectra, which were measured directly after the standard growth of the GaAsSb layers, are shown on the bottom side of Fig. 4 together with the 'reference RA spectrum' of a $200 \mathrm{~nm}$ thick GaAsSb layer grown directly on InP (100). A significant difference can be recognized in the energy range between 2.5 $\mathrm{eV}$ and $3.0 \mathrm{eV}$, where the RA spectrum of the $(4 \times 3)$-preparation has a minimum at 2.7 $\mathrm{eV}$, in contrast to the $(2 \times 4)$ - and $(4 \times 2)$-reconstructed surfaces. On the other hand, all the three GaAsSb surfaces, which were all grown As-rich, showed the identical LEED image with the expected $c(4 \times 4)$ symmetry, as shown on the bottom side of Fig. 4.

However, XPS measurements displayed significant differences, as seen on the right hand side of Fig. 4. Analyzing the As 3d and $\mathrm{Sb} 4 \mathrm{~d}$ core level peak areas, measured on the 2-nm GaAsSb on the different InGaAs surface reconstructions, indicated a much too low Sb-content for the GaAsSb layer grown on the $(4 \times 3)$-reconstructed InGaAs surface (black line). In the XP spec- tra of the 200-nm thick reference GaAsSb layer, the peak areas of the $\mathrm{As} 3 \mathrm{~d}$ and $\mathrm{Sb}$ $4 d$ levels were nearly equal. For the thin 2-nm GaAsSb layer, the As atoms from the underlying InGaAs layer also contributed additionally to the As $3 \mathrm{~d}$ peak, while the $\mathrm{Sb}$ peak originated only from the $2-\mathrm{nm}$ $\mathrm{GaAsSb}$ layer. It was estimated that the underlying InGaAs layer contributed about half of the intensity of the As 3d peak, as it was correspondingly observed for the In $3 \mathrm{~d}$ core level peak. Therefore, assuming similar stoichiometries and an abrupt interface, the As 3d XPS-peak area of the 2-nm GaAsSb on InGaAs should have been around the double of the XPS peak area measured on a pure GaAsSb layer. The GaAsSb layer growth on both $(2 \times 4)$ and (4×2)-reconstructed InGaAs surfaces, which resulted in very similar RA spectra, resulted in almost identical XP spectra with the expected peak area ratios of $\mathrm{As} 3 \mathrm{~d} / \mathrm{Sb}$ $4 \mathrm{~d}=2$. However, for the $2-\mathrm{nm} \mathrm{GaAsSb}$ layers grown on the $(4 \times 3)$-reconstructed InGaAs surface, the XPS peaks indicated a much too low Sb-content. This suggests that starting the growth of GaAsSb on III-rich $(2 \times 4)$ - or $(4 \times 2)$-reconstructed $\operatorname{InGaAs}(100)$ instead of the As-rich $(4 \times 3)$-reconstructed InGaAs(100) surface, led to more defined and sharper InGaAs/GaAsSb interfaces.

\subsection{Performance of the Tandem (Two-junction) Solar Cells}

To prepare the tandem structure, a reliable and stable layer growth for more than $2 \mu \mathrm{m}$ thickness is necessary after the interface preparation of the tunnel junction. RAS measurements showed that the MOVPE-growth of the following layers of the device structure was stable and independent of the different interface preparation methods. To evaluate the performance of the InGaAsP/InGaAs tandem solar cells, their external quantum efficiencies (EQE)

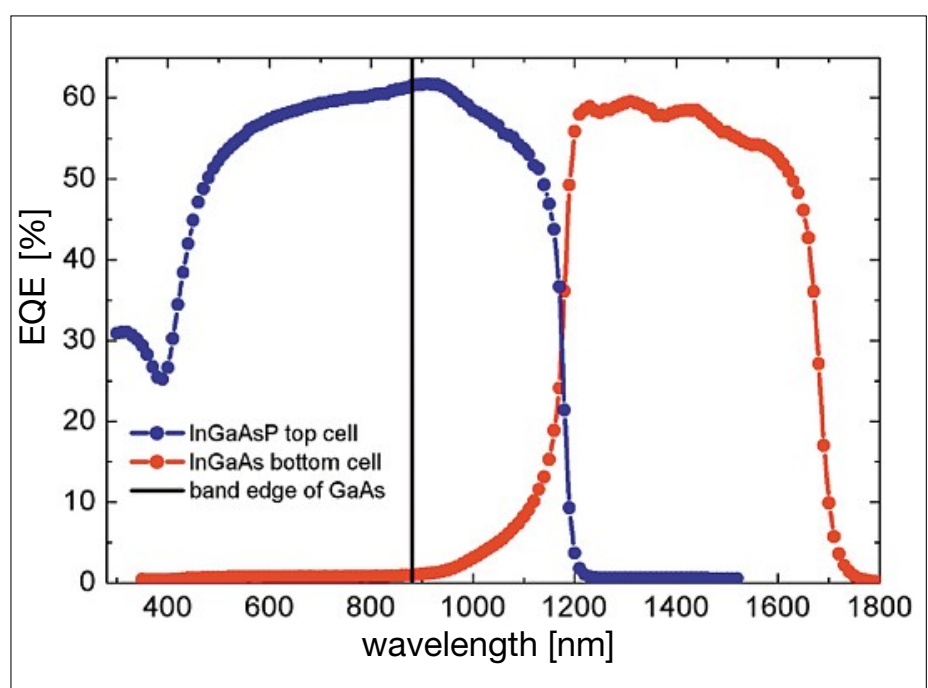

Fig. 5. External quantum efficiency (EQE) curves of the subcells of an InGaAsP/InGaAs tandem solar cell. were measured (Fig. 5). The onsets of the photocurrent at $1200 \mathrm{~nm}$ and $1700 \mathrm{~nm}$, correspond to the designed band gap energies $(1.03 \mathrm{eV}$ and $0.73 \mathrm{eV})$ of the top and bottom cells. The current mismatch between the two subcells was estimated from the spectral response curves. Since the tandem cells were designed to work under GaAs, the total currents of the subcells were calculated by integrating the curves starting from the band gap edge of GaAs. The subcell currents estimated by this procedure were 5.5 $\mathrm{mA} / \mathrm{cm}^{2}$ and $7.4 \mathrm{~mA} / \mathrm{cm}^{2}$ for the top and bottom cells, respectively. Hence, further optimization with respect to current matching will be necessary either by increasing the thickness of the top cell or by slightly decreasing the band gap of the top cell. The quantum efficiency of the bottom InGaAs cell was lower than of the top cell. This might be either due to out diffusion of $\mathrm{Zn}$ from the $\mathrm{p}^{+}$-InGaAs back scattering field (BSF) layer or due to a too thin InGaAs absorber. Co-doping and thin diffusion barriers will be tested and implemented in the short term. In addition, the thickness of the bottom cell will be increased from $3 \mu \mathrm{m}$ to $4 \mu \mathrm{m}$, in order to increase the quantum efficiency at the absorption edge.

The conversion efficiencies were measured under a AM1.5 solar spectrum with a cut-off filter (Schott RG850) that blocks the wavelengths up to $850 \mathrm{~nm}$. This should simulate the operation of the low band gap tandem solar cell under a GaAs-based high band gap solar cell. Regarding the I-V characteristics we did not observe any current limiting effects up to a concentration of 50 suns, corresponding to current densities of $\mathrm{J} \geq 500 \mathrm{~mA} / \mathrm{cm}^{2}$ at the tunnel diode. Preliminary work on tandem solar cells, which were prepared identically except for the In$\mathrm{GaAs} / \mathrm{GaAsSb}$ interface preparation routes at the tunnel junction, have shown a slightly better performance for cells prepared using 
the III-rich InGaAs surface. This rather indicates a favorable growth for the top cell absorber, since the tunnel junction should not be a limiting factor at our operating conditions of the cell. The I-V curve of the best cell prepared via the III-rich InGaAs route is shown in Fig. 6. An efficiency of $7.9 \%$ was measured (in-house) at a concentration ratio of 13 suns below the RG850 filter for the tandem cell without an anti-reflective coating (ARC). Considering the current results and the envisaged improvements we are expecting to reach the projected practical efficiency of $9.5 \%$ for 15 suns below a GaAs filter. ${ }^{[25]}$ These efficiency values are all significantly higher than the experimental and theoretical efficiencies for a Ge subcell operating under GaAs. The best efficiency value that has been achieved with a Ge subcell under GaAs was $4.6 \%{ }^{[26]}$ The theoretical efficiencies of a Ge subcell under a GaAs filter were calculated to be $3 \%$ for one sun and $5.8 \%$ for 300 suns excluding optical and electrical losses. ${ }^{[27]}$ Therefore, replacing the Ge subcell with the more efficient low band gap InGaAsP/InGaAs tandem cell will significantly improve the conversion efficiency of the multijunction solar cells.

\section{Conclusion}

The conversion efficiency of the metamorphic triple junction world record solar cell could be improved significantly if its Ge subcell would be replaced with a more efficient tandem (two-junction) III-V solar cell. The resulting four-junction configuration with optimum band gaps could be realized by means of grading, spectral beam splitting, mechanical stacking, or wafer bonding. For this purpose, low band gap InGaAsP/InGaAs tandem solar cells (1.03 $\mathrm{eV}, 0.73 \mathrm{eV}$ ) were grown monolithically and lattice-matched on InP (100) wafers. The two subcells were connected by a tunnel diode, which was composed of thin and highly doped $\mathrm{n}^{++}$-InGaAs and $\mathrm{p}^{++}$-GaAsSb layers. By means of surface sensitive measurement methods like RAS and LEED, a reproducible procedure was developed to prepare three different surface reconstructions $\{(4 \times 3),(2 \times 4)$ and $(4 \times 2)\}$ on the InGaAs surface via MOVPE. XPS measurements showed that the growth of the thin GaAsSb layers on the As-rich, $(4 \times 3)$-reconstructed InGaAs surface led to a much too low Sb-content in the first monolayers of the $\mathrm{InGaAs} / \mathrm{GaAsSb}$ interface formation. Therefore, sharper InGaAs/GaAsSb interfaces in the tunnel junction were achieved when the GaAsSb layer was grown on the III-rich $\{(2 \times 4)$ or $(4 \times 2)\}$ InGaAs surface. Efficiencies of about $7.9 \%$ were achieved for the tandem solar cells below an optical RG850 filter without anti-reflective coat-

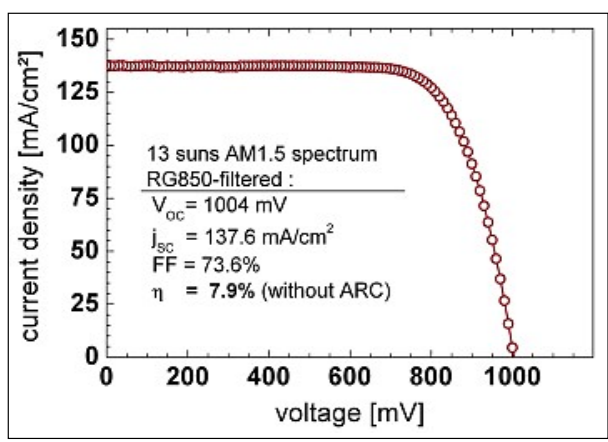

Fig. 6. I-V curve of the best InGaAsP/InGaAs tandem solar cell without anti-reflective coating.

ings (ARCs). We are expecting to reach the projected practical efficiency limit of 9.5\% below GaAs after realizing appropriate ARCs. These values are considerably higher than $4.6 \%$, which was the best ever reported efficiency for a Ge subcell below GaAs.

\section{Acknowledgements}

The authors would like to thank W. Albrecht for the calculations of the limiting conversion efficiencies and G. Siefer (Fraunhofer ISE in Freiburg) for the EQE measurements.

Received: October 29, 2007

[1] M. A. Green, K. Emery, D. L. King, Y. Hisikawa, W. Warta, Prog. Photovolt: Res. Appl. 2007, 14, 35.

[2] M. R. Reddy, Sol. En. Mat. \& Sol. Cells 2003, 77, 175 .

[3] S. Kurtz, D. Friedman, J. Geisz, W. McMahon, J. Cryst. Growth 2007, 298 , 748.

[4] W. Shockley, H. J. Queisser, J. Appl. Phys. 1961, 32, 510 .

[5] R. R. King, D. C. Law, K. M. Edmondson, C. M. Fetzer, G. S. Kinsey, H. Yoon, R. A. Sherif, N. H. Karam, Appl. Phys. Lett. 2007, 90, 183516.

[6] A. Marti, G. L. Araujo, Sol. En. Mat. \& Sol. Cells 1996, 43, 203.

[7] A. J. Ptak, D. J. Friedman, S. Kurtz, R. C. Reedy, J. Appl. Phys. 2005, 98, 094501.

[8] F. Dimroth, C. Baur, A. W. Bett, K. Volz, W. Stolz, J. Cryst. Growth 2004, 272, 726.

[9] J. F. Geisz, S. Kurtz, M. W. Wanlass, J. S. Ward, A. Duda, D. J. Friedman, J. M. Olson, W. E. McMahon, T. E. Moriarty, J. T. Kiehl, Appl. Phys. Lett. 2007, 91, 023502 .

[10] A. G. Imenes, D. R. Mills, Sol. En. Mat \& Sol. Cells 2004, 84, 19.

[11] T. Yamada, A. Motto, Y. Iguchi, M. Takahashi, S. Tanaka, T. Tanabe, S. Tánaistí, Jap. J. Appl. Phys. 2005, 44. 988.

[12] K. Tanabe, A. Fontcuberta i Morral, H. A. Atwater, D. J. Aiken, M. W. Wanlass, Appl. Phys. Lett. 2006, 89, 102106.

[13] G. Létay, A. W. Bett, Proc. 17th EU PV Sol. En. Conf. 2001, 178.

[14] G. Létay, Ph.D. Thesis, University of Konstanz, Germany, 2003.
[15] F. Dimroth, R. Beckert, M. Meusel, U. Schubert, A. W. Bett, Prog. Photovolt. 2001, 9, 165.

[16] C. M. Fetzer, H. Yoon, R. R. King, D. C. Law, T. D. Isshiki, N. H. Karam, J. Cryst. Growth 2005, 276, 48.

[17] L. Esaki, Phys. Rev. 1958, 109, 603.

[18] U. Seidel, Ph.D. Thesis, Humboldt University of Berlin, Germany, 2007.

[19] T. Hannappel, S. Visbeck, L. Töben, F. Willig, Rev. Sci. Inst. 2004, 75, 1297.

[20] U. Seidel, H. J. Schimper, Z. Kollonitsch, K. Möller, K. Schwarzburg, T. Hannappel, J. Crys. Growth 2007, 298, 777.

[21] P. A. Bone, J. M. Ripalda, G. R. Bell, T. S. Jones, Surface Science 2006, 600, 973.

[22] J. Mirecki Millunchick, A. Riposan, B. J. Dall, C. Pearson, B. G. Orr, Surface Science 2004, 550, 1.

[23] W. G. Schmidt, Appl. Phys. A 2002, 75, 89.

[24] Z. Kollonitsch, H. J. Schimper, U. Seidel, K. Möller, S. Neumann, F. J. Tegude, F. Willig, T. Hannappel, J. Crys. Growth 2006, 287, 536.

[25] J. M. Zahler, A. Fontcuberta i Morral, C. G. Ahn, H. A. Atwater, M. W. Wanlass, C. Chu, P. A. Iles, 29th IEEE PV Spec. Conf. 2002, 1039.

[26] C. Baur, M. Meusel, F. Dimroth, A. W. Bett, Proc. 31st IEEE PV Spec. Conf. 2005, 675 .

[27] B. Sautreuil, A. Laugier, Sol. En. Mat. 1981, 5, 21. 